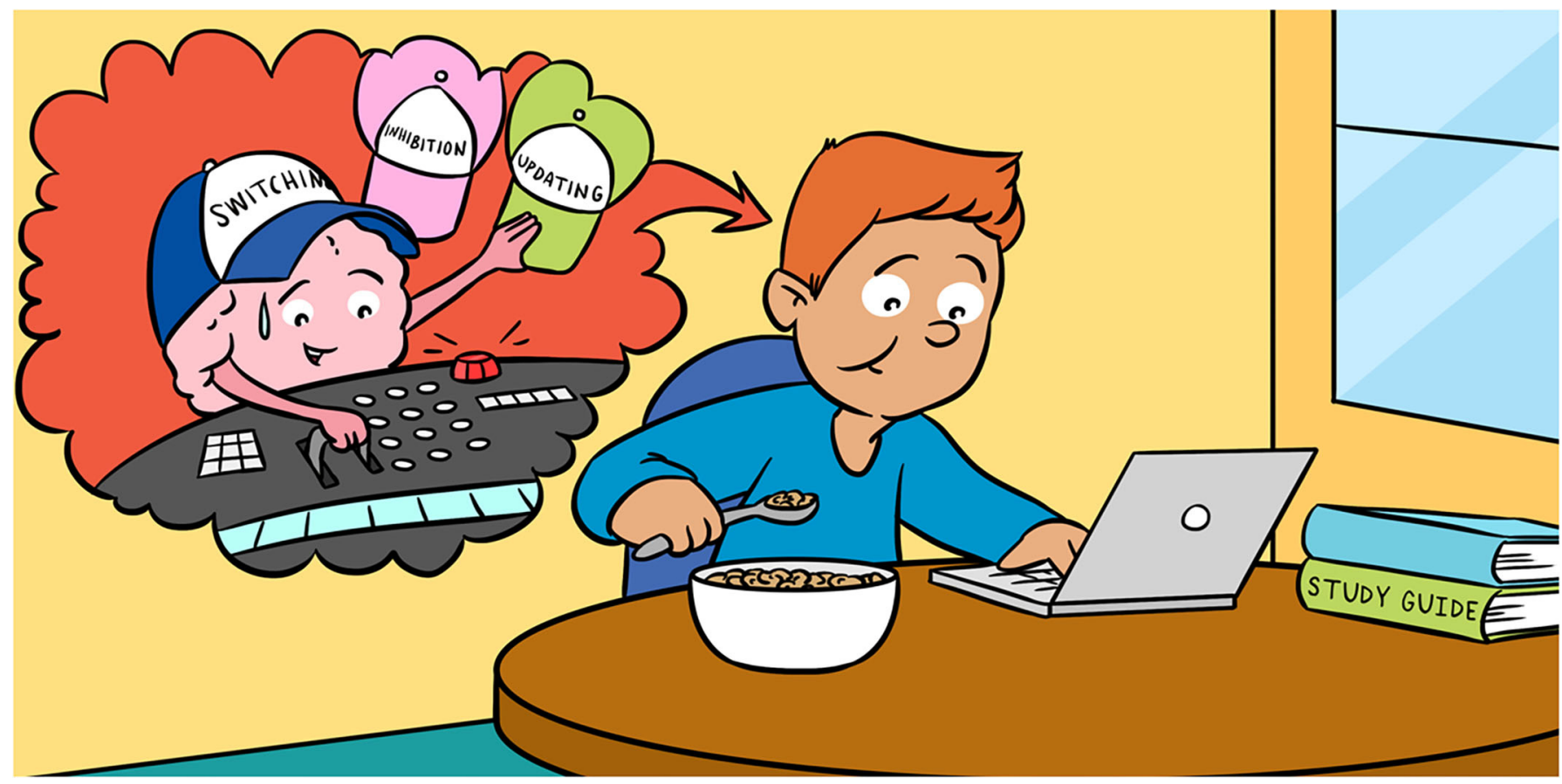

\title{
A CORE SET OF BRAIN REGIONS HELPS KIDS ACHIEVE THEIR GOALS
}

\section{AnnaCarolina Garza ${ }^{1+}$, Alice Aizza ${ }^{1+}$, Janchira K. Charoenworawat ${ }^{1 \dagger}$ and Jessica A. Church ${ }^{1,2^{*}}$ \\ ${ }^{1}$ Department of Psychology, The University of Texas at Austin, Austin, TX, United States \\ ${ }^{2}$ Biomedical Imaging Center, The University of Texas at Austin, Austin, TX, United States}

\section{YOUNG REVIEWERS:}
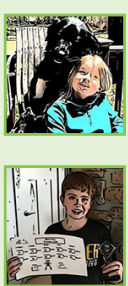

.
KENLEY

AGE: 8

PARKER

AGE: 10

NEHA

AGE: 9
Your brain is always adjusting to the changing swirl of activities and interactions you have every day. Every time you accomplish a goal, you are exercising what are called the brain's executive functions. These skills include resisting impulses, switching between tasks, and updating information in your memory. We asked whether these different skills relied on the same brain areas, and whether young people used the same brain areas as adults. We took pictures of kids' and teens' brains to see which areas of the brain they were using while they played three simple games related to these executive functions. We found that youth used similar brain regions to adults while playing the three games, and that many parts of the brain were used across all three games. These results help us understand how kids use their brains to be successful and how these skills develop. 


\section{EXECUTIVE}

\section{FUNCTIONS (EFs)}

The brain's abilities that coordinate our thoughts and behaviors, to help us achieve our goals.

\section{INHIBITION}

An executive function that helps us resist distraction or doing things we do not want to do.

\section{SWITCHING}

An executive function that helps us flexibly shift between multiple sets of rules or activities.

\section{UPDATING}

An executive function that helps us monitor for new information and incorporate it into our memories and current plans.

Figure 1

Inhibition, switching, and updating are examples of the brain's control skills, which we use every day to do big and small things.

\section{YOUR BRAIN CHANGES TO ACCOMPLISH YOUR GOALS}

*Ring!* Your alarm alerts you that it is time to wake up for school. Today you are presenting a major project in science class, and you do not want to be late. However, although you try to resist, you end up hitting the snooze button several times, and now you are running late! You want to be prepared for your presentation, so you decide to multitask by reviewing your project while you eat breakfast, switching between eating and reading your materials. When you get to school and start your presentation, you try to remember all the rules for the assignment, like speaking clearly and making eye contact, and check them off in your head to make sure you are doing a great job (Figure 1).

This example demonstrates how we use our brains to adjust to changes in the environment all the time, and how we can organize our behaviors toward a specific goal, like giving a great presentation at school. Having the abilities to remember and update information (like presentation rules and our goals), to resist our impulses (like hitting the snooze), and to switch between tasks (like breakfast and schoolwork), are very useful when there are multiple demands competing for our time and energy, and when a few unexpected obstacles happen, too.

The scenario above may sound familiar to you if you have ever been in a situation that required you to be flexible and think of new solutions to sudden problems. Many researchers want to know when, where, and how the brain develops these executive functions (EFs), or the skills we use to accomplish our goals. Research suggests there are many distinct types of EFs at play as we navigate through daily life, but we will highlight the three we have just introduced: (1) inhibition, which helps us resist inappropriate responses; (2) switching, which helps us mentally shift between multiple sets of rules or standards; and (3) updating, which helps us monitor for new information and incorporate it into our memories and current plans [1]. When we
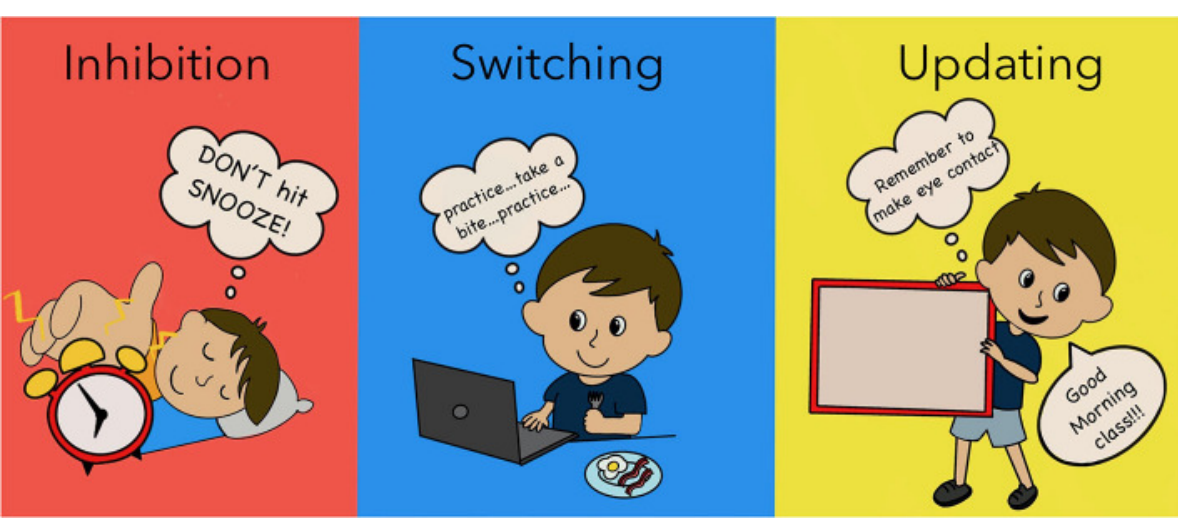

Figure 1 
Figure 2

To test which parts of the brain they use for executive functions, and whether these are the same brain areas adults use, children (ages 8-14) played three different games while inside an fMRI scanner that measured brain activity.

\section{COGNITIVE CONTROL}

The collection of abilities that we use to do what we want. Different executive functions make up our overall cognitive control ability, which we engage anytime we choose to do something. Cognitive control is often studied when we compare doing something hard to doing something easy, and you get better at cognitive control throughout childhood and adolescence.

\section{CORE CONTROL} SYSTEM

Parts of the brain used for many challenging tasks, such as those that involve executive functions or cognitive control. The black regions in Figure 3 are part of the core control system.

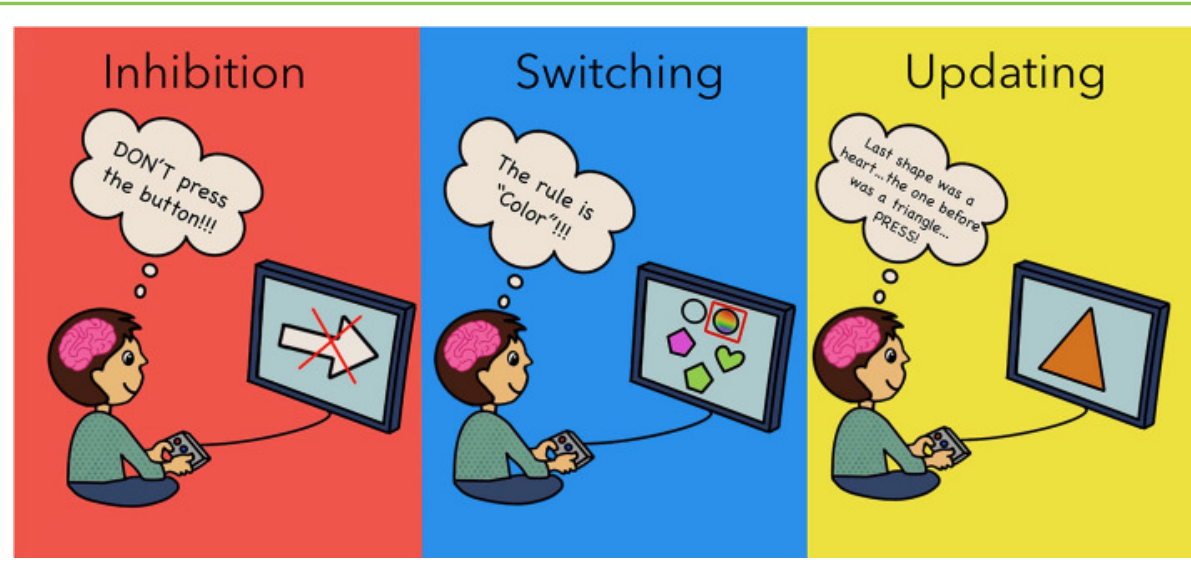

Figure 2

use these and other EFs to accomplish a complicated task, scientists describe this overall ability as cognitive control [2]. By using greater cognitive control, we can make fast and correct responses, adjust to changing conditions, and juggle different tasks with ease. Cognitive control is the effective use of the brain's EFs to achieve our goals, do well at school, and even feel good about ourselves and handle stressful times [2].

\section{DO KIDS AND ADULTS USE THE SAME BRAIN REGIONS TO ACHIEVE THEIR GOALS?}

Depending on the goal, different EFs may be used to achieve it. We wondered whether children and teenagers used the same or different parts of the brain to perform three different EFs. To make sure all our study participants were using the same EFs at the same time, we had people ages 8-14 years old play the same three computer games (Figure 2).

You might guess that adults have pretty good cognitive control, since they get a lot of practice juggling work, chores, money, cars, and more (though even adults struggle with cognitive control and with achieving their goals sometimes!)! A study of adults' brains revealed a set of brain regions that are all active when doing various EF tasks. Researchers broadly refer to this web of interconnected brain regions as the core control system because it consists of key brain areas that are used together when we do challenging things [4]. Because EF skills are so important for success in school and life, we wondered if kids engage the same core control system as adults, or if they use different brain regions for EF tasks [5]. Most studies have looked at EFs in kids using only one task. We took pictures of kids' brains while they played three different EF games, and we compared the brain regions to answer two questions. First, in kids, do the three EF tasks all use similar brain regions, the way adult brains do? And second, are the brain regions kids use for EF tasks the same brain regions that adults use? 
Figure 3

The right half of the brain is shown, as if a person was facing the same way as Figure 2. The areas of brain activity during each of the three EF games, indicated by the colors in the key, are shown in the top row. The brain at the center shows the overlapping brain regions, indicating regions that are used for any two, or all three, of these games. You can see that many brain regions are used by at least two tasks. The black areas (used in all three tasks) overlap with core control brain regions seen in adults (Adapted with author permission from [5]).

\section{FUNCTIONAL}

\section{MAGNETIC}

RESONANCE

IMAGING (fMRI)

A scanning tool to study how the brain works. It uses magnets and radio waves (not radiation!) to take lots of pictures of the brain over several minutes. Researchers can learn which parts of the brain are used when people do or think about different things by presenting pictures or sounds to the participant during the brain scan.

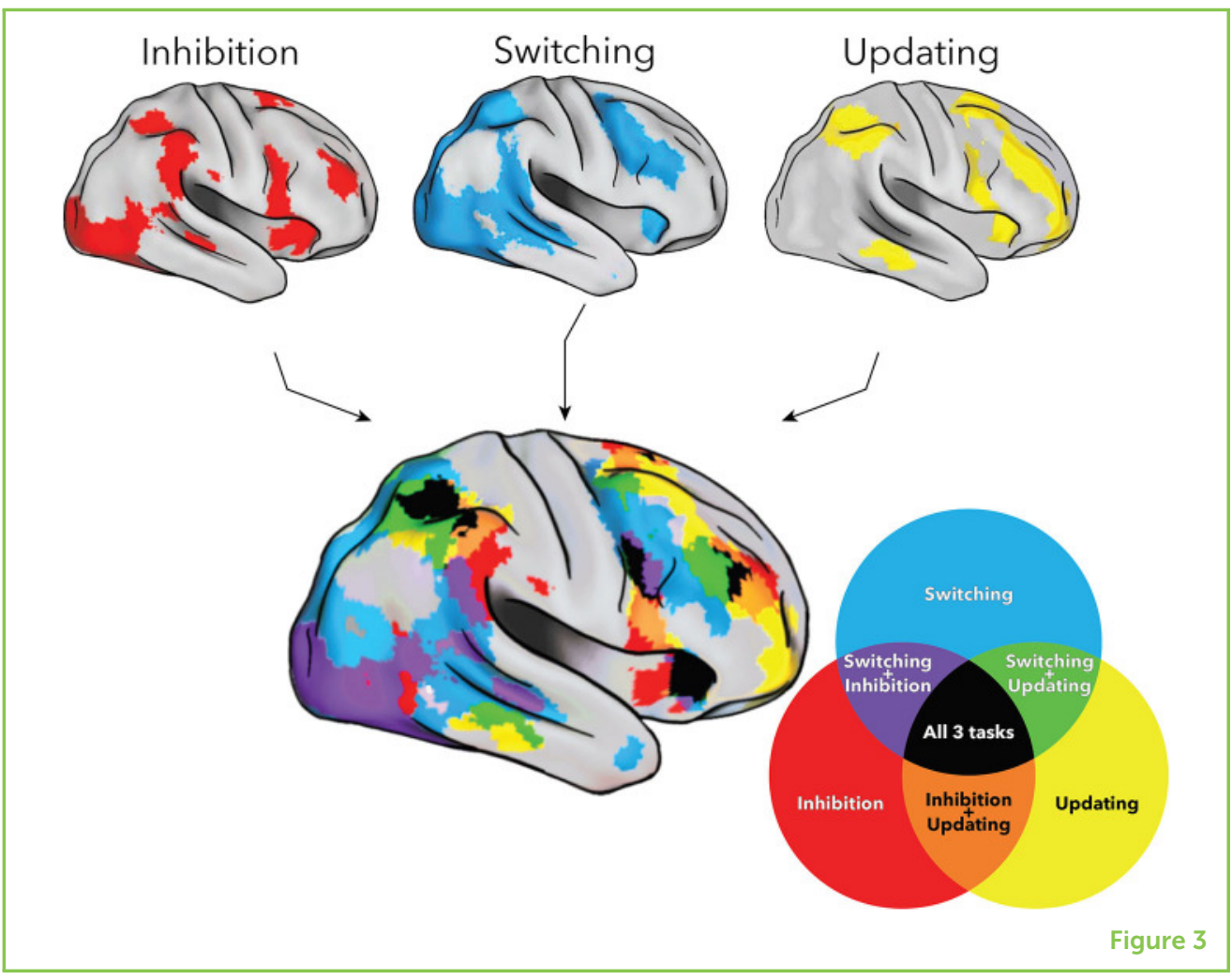

\section{PLAYING GAMES TO MEASURE EFS IN THE BRAIN}

One of the tools used to study the human brain is called functional magnetic resonance imaging (fMRI). An fMRI scanner is a machine with a large magnet that allows us to take hundreds of pictures of the brain and measure changes in the activity of the brain over time. It does this by detecting changes in oxygen levels and blood flow in the brain while the scanned person is playing games, watching a movie, or just resting. In our study, 117 children (ages 8-14 years) from Texas played three EF games in the fMRI scanner, which allowed us to see which brain regions were active during each of the games. Participants lay on their backs inside the MRI scanner used a mirror to view a computer screen. They held two buttons in their hands to play the games while we took pictures of their brains.

In the inhibition game, kids pressed a button as quickly as they could to indicate which direction a single arrow was pointing (left or right), as it changed randomly. They did a lot of button presses quickly, unless a red " $X$ " appeared on top of the arrow. When that happened, kids had to resist pressing any buttons. This was tricky because sometimes the red X showed up quickly, and sometimes it was slow. In the switching game, kids were told to sort different colorful shapes by either their color or shape. The rule to sort by color or shape switched randomly, so kids had to pay attention, because if they sorted by the wrong rule, they would get the wrong answer. Finally, in the updating game, kids saw a quickly moving line of green shapes on the screen (square, 
triangle, square). They had to remember the order of shapes, because they needed to press a button when the shape on the screen matched the one they saw two shapes previously.

\section{WHAT DID WE FIND?}

Our experiment helped us to answer our two main questions! First, we found that several regions of the brain were active in all three games, meaning that the EF games used similar parts of the brain (Figure 3). Second, we found that the EF brain regions used by kids were the same as those used by adults. Brain activity that was seen across two or all three games agreed with many adult brain results, including regions of the core control system.

\section{WHAT DO OUR RESULTS HELP US UNDERSTAND?}

These results show that a common set of brain regions that support EFs is similar in adults and kids as young as 8 years old. However, more research is needed to understand how our EF skills and goal setting improve as we get older. The work happening within the brain's core control system is likely still improving over time and with practice of different skills, even in adults.

We can think about the results of this study in several different ways. First, kids are similar to adults in that they are using the same parts of the brain that adults use for achieving their goals. Second, the brain's EFs are important in school and life-we use them every day! Understanding how we work to complete a task and how EFs change as we age is important to create new ways to improve EFs in all kids. EF skills can vary in different individuals, and this research suggests that these differences might begin in the core control system of the brain. The results we find in healthy kids could be compared to studies looking at children with brain difficulties or who have learning differences, and this could lead to therapies that will help kids who struggle with EF skills.

There are several fun games and activities that people can do to practice their cognitive control skills. Think about activities that practice switching between things, holding and working with ideas in mind, and resisting distractions. Organized sports, like soccer, improve cognitive control skills because players practice holding the rules of the game in mind, cooperating with others, and monitoring the quickly changing environment around them. Group card or board games in which players must think flexibly about language, inhibit their first guesses, or balance multiple goals can also give kids good practice with cognitive control skills. When people have trouble with cognitive control skills, creating a checklist of smaller steps needed to do a 
task, and working on big projects one step at a time, can help make complicated projects easier.

In summary, cognitive control regions in the brain are used to across many different tasks to help us achieve our goals. This research project tested three different EF tasks in the same children, and revealed a common core control system. These brain regions are similar across children and adults, suggesting that as we get better at cognitive control, brain connections, rather than brain locations, are changing. Cognitive control improves with age and practice, and uses many parts of the brain each time it is put to use. We thank all of the families who helped with this project.

\section{ORIGINAL SOURCE ARTICLE}

Engelhardt, L. E., Harden, K. P., Tucker-Drob, E. M., and Church, J. A. 2019. The neural architecture of executive functions is established by middle childhood. Neuroimage 185:479-89. doi: 10.1016/j.neuroimage .2018.10.024

\section{REFERENCES}

1. Miyake, A., Friedman, N. P., Emerson, M. J., Witzki, A. H., Howerter, A., and Wager, T. D. 2000. The unity and diversity of executive functions and their contributions to complex "frontal lobe" tasks: a latent variable analysis. Cogn. Psychol. 41:49-100. doi: 10.1006/cogp.1999.0734

2. Church, J. A., Bunge, S. A., Petersen, S. E., and Schlaggar, B. L. 2017. Preparatory engagement of cognitive control networks increases late in childhood. Cerebral Cortex 27:2139-53. doi: 10.1093/cercor/bhw046

3. Luna, B., Garver, K. E., Urban, T. A., Lazar, N. A., and Sweeney, J. A. 2004. Maturation of cognitive processes from late childhood to adulthood. Child Dev. 75:1357-72. doi: 10.1111/j.1467-8624.2004.00745.x

4. Dosenbach, N. U. F., Fair, D. A., Miezin, F. M., Cohen, A. L., Wenger, K. K., Dosenbach, R. A. T., et al. 2007. Distinct brain networks for adaptive and stable task control in humans. Proc. Natl. Acad. Sci. 104:11073-8. doi: $10.1073 /$ pnas. 0704320104

5. Engelhardt, L. E., Harden, K. P., Tucker-Drob, E. M., and Church, J. A. 2019. The neural architecture of executive functions is established by middle childhood. Neuroimage 185:479-89. doi: 10.1016/j.neuroimage.2018.10.024

SUBMITTED: 16 October 2020; ACCEPTED: 16 July 2021; PUBLISHED ONLINE: 12 August 2021.

EDITED BY: Ryan E. B. Mruczek, College of the Holy Cross, United States

CITATION: Garza A, Aizza A, Charoenworawat JK and Church JA (2021) A Core Set of Brain Regions Helps Kids Achieve Their Goals. Front. Young Minds 9:618432. doi: $10.3389 /$ frym.2021.618432 

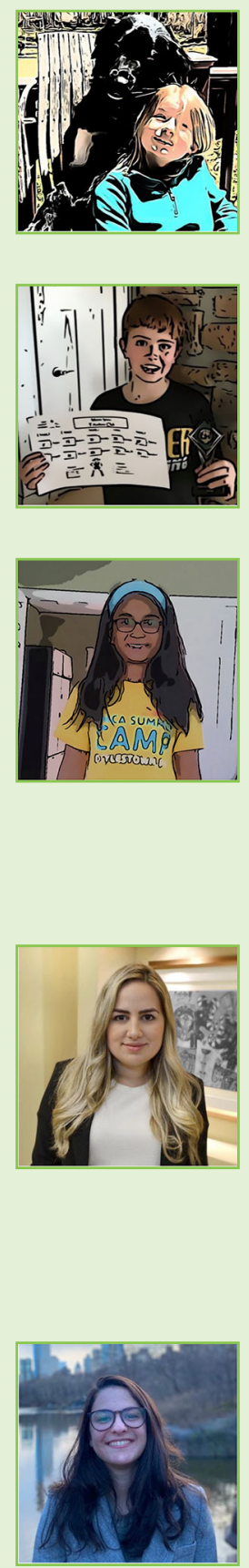

CONFLICT OF INTEREST: The authors declare that the research was conducted in the absence of any commercial or financial relationships that could be construed as a potential conflict of interest.

COPYRIGHT @) 2021 Garza, Aizza, Charoenworawat and Church. This is an open-access article distributed under the terms of the Creative Commons Attribution License (CC BY). The use, distribution or reproduction in other forums is permitted, provided the original author(s) and the copyright owner(s) are credited and that the original publication in this journal is cited, in accordance with accepted academic practice. No use, distribution or reproduction is permitted which does not comply with these terms.

\section{YOUNG REVIEWERS}

\section{KENLEY, AGE: 8}

I am an 8 year old girl who likes running, driving a razor, and gymnastics. My favorite food is stuffed shells. In school I like PE and math.

\section{PARKER, AGE: 10}

I am a 10 year old boy who really likes to do sports. My favorite is wrestling. Writing is my favorite subject in school. My hobbies include building things, sports, and driving my razor around.

\section{NEHA, AGE: 9}

Neha loves sports, riding horses, swimming, and reading books. She is very interested in learning everything she can about horses and dogs, and loves learning about the human body. She is excited about reading articles and learning more things about science.

\section{AUTHORS}

\section{ANNACAROLINA GARZA}

AnnaCarolina is currently studying neuroscience as an undergraduate at the University of Texas, and she works as a research assistant in the Developmental Cognitive Neuroscience Lab there. She really enjoys working with kids and performing research that helps improve our understanding of how the brain works and develops. She plans on pursuing a career in the neuroscience field and continuing to do research. In her free time, you can find her reading a book, riding her bike, playing golf, or spending time with her family and friends.

\section{ALICE AIZZA}

Alice Aizza is an undergraduate student at the University of Texas at Austin. She studies psychology and sociology and is a research assistant in Dr. Church's Developmental Cognitive Neuroscience lab. She is fascinated by the brain and behavior, and she is especially interested in developmental 

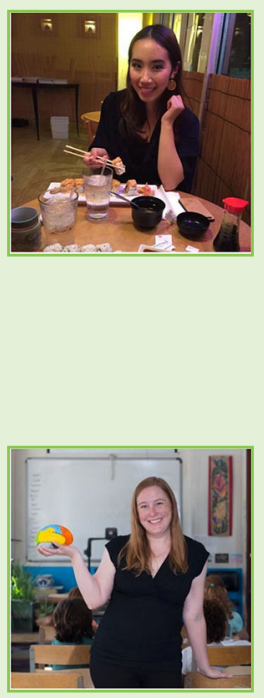

disorders and neuroimaging. Aside from that, she enjoys reading, swimming, and being outdoors.

\section{JANCHIRA K. CHAROENWORAWAT}

Janchira graduated with her Bachelor of Science in psychology from the University of Texas at Austin in 2020. From a young age, she has been interested in learning how the brain develops to support basic human processes like thinking, feeling, and behaving. She especially enjoys working with people from all walks of life and hopes 1 day to help individuals living with serious mental health conditions. When she is not admiring pictures of brains, she can be found watching crime investigative TV shows at home with her cat.

\section{JESSICA A. CHURCH}

Jessica Church is an associate professor of psychology at the University of Texas at Austin in Austin, Texas, USA. She received her Ph.D. in neuroscience at Washington University in St. Louis. Jessica runs the Developmental Cognitive Neuroscience lab, where she and other lab members enjoy studying how the brain controls behavior, and how kids improve in skills like reading and math. When not having fun in the lab, Jessica can be found reading, jogging, drinking tea, or playing games of all sorts with her family-especially with her two daughters. * church@austin.utexas.edu

${ }^{\dagger}$ These authors have contributed equally to this work 